\title{
O MITO DE FRANKENSTEIN: O AMOR NEGADO E DENEGADO
}

Roberto Ramos*

SÍNTESE - Frankenstein é um dos personagens mais populares da ficção. Nascido no romance de Mary Shelley, ele está completando 180 anos, mas já transcendeu as fronteiras da literatura. Há 65 anos, é encontrado nas telas cinematográficas, somando 117 aparições, perdendo apenas para o Conde Drácula, com 161, no gênero de filmes de terror. Este ensaio, atravessado por suas precariedades e limitações históricas, procurará respostas sobre o mito de Frankenstein. É importante investigar as significações desta experiência de alma, que the asseguram atualidade e permanência às vésperas do terceiro milênio. Para tanto, serão usados os pressupostos da Psicanálise, compatibilizados com os do filósofo Louis Althusser.
ABSTRACT - Frankenstein has a great popularity as a character in fiction literature. Like a creation of Mary Shelley's romance, he is today 180 years old and was transcend the frontiers of the literature. About 65 years we courd see him at the movies with 117 appearances, losing only for Dracula with 161 appearances in terror movies. The paper in question, with several historical limitations, intends to look some answers about Frankenstein myth. It is inportant to search the sense of this soul experience, because he is a real and durable character until this 3 rol millenium eve. For this story will be used a Psychoanalysis theory in association of Louis Althusser philosophy.

A paisagem humana tem mudado de cenário nos mais diferentes momentos da História. Desde as cavernas até as vésperas do século XXI, faitam dedos, para contar as incontáveis mudanças. Há, porém, um protagonista, que não arreda o pé do palco: a família, o berço da socialização, que embala os laços biológicos e entoa cantigas de modelagem cultural.

Neste breve artigo, envolvido pelas suas precariedades e limitações, haverá o objetivo de analisar a importância da família, através, sobretudo, de categorias da Psicanálise e de Louis Althusser. Posteriormente, ocorrerá um exame do papel familiar no mito de Frankenstein.

\section{Aie familiar}

A família é uma onipresença no script da subjetividade. Nas mais diversas cenas, tomadas e takes, que perfazem o enredo humano, a sua participação é uma invariante. Transcende as fronteiras dos idiomas, das geografias, com várias faces, mas com o mesmo rosto familiar.

Faculdade dos Meios de Comunicação Social (FAMECOS) da PUCRS.

\begin{tabular}{|l|l|l|l|l|l|}
\hline VERITAS & Porto Alegre & v. 41 & $n^{2} 164$ & Dezembro 1996 & p. 729-735 \\
\hline
\end{tabular}


Natthan W. Ackerman consegue detectar, com nitidez, a presença desta instituição primária nas diferentes etapas da trajetória da caminhada humana: ${ }^{1}$

"... Cada homem não tem uma família, mas diversas. Ele tem a família de sua infância, a família por casamento e paternidade e a familia poente - a família com os netos. Em cada um destes períodos, de vida familiar, o indivíduo deve integrar suas disposições emocionais nos papéis familiares adequados".

Ackerman coloca em pauta uma característica da subjetividade: a sociabilidade. O homem é, por excelência, um ser social. Vive e convive sob aos auspícios da interação com o grupo, tendo como paradigma a perspectiva do contexto sócio-histórico.

Sigmund Freud estabelece a influência familiar por intermédio do Superego, um dos conceitos estruturais do aparelho psíquico. Ele oferece explicações: ${ }^{2}$

\begin{abstract}
"A psique (o aparelho mental) começa o seu desenvolvimento como Id desorganizado, do qual o Ego se desenvolve no curso de sua relação com o meio ambiente. O Superego se desenvolve a partir do Ego, em consequiência do Complexo de Édipo. Enquanto o Id (processo primário) procura caminho para a satisfação imediata dos impulsos, o Ego possibilita ao individuo o adiamento da satisfação e o controle do meio ambiente. O Superego representa a figura dos pais introjetada (normas sociais). A severidade do Superego origina-se, em parte, da violência dos sentimentos infantis; pode se dirigir contra o próprio indivíduo em forma de agressão para dentro de si mesmo".
\end{abstract}

O recém-nascido é um território dominado pelo instinto. Está comprometido com a dimensão inata. Prevalece a perspectiva biofísica, pela manifestação do processo primário. É puro Id, um animalzinho humano que, gradativamente, se converterá em sujeito, pela linguagem, no habitat da família.

Louis Althusser ${ }^{3}$ fixa a relação dialética, que envolve o conceito de sujeito. Significa o ser livre para traçar, com os seus passos, o mapa do seu existir. Todavia, significa também o submisso, a reboque de um outro, atrelado a um senhorio.

Através da linguagem, o indivíduo começa a se revestir da condição de sujeito. Os pais funcionam como espelhos. Produzem reflexos na relação com os filhos, que os internalizam no Superego, o reduto da socialização e da idealidade.

Freud assinala as fases do desenvolvimento humano, em que a libido (energia que "flui" nos processos, estruturas e objetos psíquicos) evolui e se concentra em diferentes regiões anatômicas: ${ }^{4}$

"O primeiro estágio de organização é o oral, em que a Libido concentra-se na boca... A segunda fase da organização da Libido é a sádico-anal, em que aparecem o instinto parcial do sadismo e a satisfação erótica, ligada às funções de excreção e retenção das fezes... Por volta dos cinco anos, começa um período de latência, durante o qual desaparecem as manifestações dos instintos parciais, em virtude da repressão, realizada pelos adultos nos estágios

ACKERMAN, Nathan W. Diagnóstico das relaçōes familiares. Porto Alegre: Artes Médicas, 1986, p. 31.

2 FREUD, Sigmund apud CLARET, Martin. O pensamento vivo de Freud. 4. ed. São Paulc: Martin Claret, 1986, p. 100-101.

3 ALTHUSSER, Louis. Aparelhos ideológicos de Estado. 2. ed. Rio de Janeiro: Graal, 1985, p. 103 e 104.

4 FREUD, Sigmund. Freud. Coleção Os Pensadores. São Paulo: Abril Cultural, 1978, p. 9. 
anteriores. Neste período de latência, as normas sociais já se encontram interiorizadas na criança, formando a consciência moral e dando nascimento ao 'ideal do eu'."'

Observa-se que a construção da subjetividade é um processo, marcado e demarcado pela presença de conflitos. É uma espécie de uma maratona de um perde-ganha incessante. A conquista de um crachá de sujeito possui um preço alto, pago com os epitáfios de muitos desejos sepultados, por vezes, sem a solenidade das lágrimas, no curso anônimo de uma rotina.

Althusser ${ }^{5}$ formula uma Teoria de Ideologia em Geral, contemplando duas teses básicas. Primeira: ela é uma relação imaginária que os indivíduos têm com as suas condições reais de existência. Segunda: possui materialidade. Transforma 0 indivíduo concreto em sujeito concreto, que é livre, para se submeter na performance da existência.

Na Ideologia, há um sujeito absoluto (uma abstração, um espelho imaginário). Neste, os sujeitos relativos (históricos) devem se espelhar, livremente, para se submeter a ele. Tais práticas e rituais ganham materialidade nos Aparelhos Ideológicos de Estado (AIE).

Os AIE são instituições distintas e especializadas, mas, em suas linguagens específicas, orquestram a Ideologia Dominante. São os seguintes: o religioso (o sistema de diferentes igrejas), o escolar (o sistema de escolas públicas e privadas), o político (o sistema eleitoral e partidário), o familiar, o jurídico, o sindical, o cultural e o de informação (a imprensa, o rádio e a televisão). ${ }^{6}$

O AIE familiar, em diversas épocas e configurações sociais, mantém uma primazia, inclusive cronológica em relação aos demais. É o primeiro responsável pela socialização no processo de desenvolvimento humano. Instaura o momento mítico da gênese das relações, que farão dos filhos uma imagem e uma semelhança dos pais, os seus paradigmas primordiais na perspectiva de ser.

\section{O mito de Frankenstein}

O romance Frankenstein, escrito por Mary Shelley, ${ }^{7}$ em 1816, tem transcendido os muros da literatura. Há 65 anos vem recebendo inúmeras versões cinematográficas. O mito não se perdeu na voragem de 180 anos. Permanece atual. Faz revelações sobre a condição da subjetividade.

Os filmes de terror surgiram na Alemanha após a Primeira Guerra Mundial. Passaram a ter maior notoriedade, na década de 20, nos Estados Unidos. Neste gênero, o personagem Frankenstein é o segundo mais popular. Teve aparições em 117 películas, perdendo apenas para o Conde Drácula, com $161 .^{8}$

A primeira versão de Frankenstein ocorreu em 1931, feita por James Whale. Ao longo de mais de seis décadas, muitas adaptações aconteceram. Vale recordar, entre outras, O jovem Frankenstein, de Mel Brooks, Frankenstein, o monstro das tre-

\footnotetext{
5 ALTHUSSER, Louis. Ibidem., p. 85 e 89.

6 Id. ibidem., p. 68.

7 SHELLEY, Mary. Frankenstein. 3. ed. Porto Alegre: L\&PM, 1985, p. 12.

8 MATTEWS, Peter (org.). Guinness Book 96. Săo Paulo: Três, 1995, p. 160.
} 
vas, de Roger Corman, e Frankenstein, de David Warner. A mais recente foi Frankenstein de Mary Shelley, do diretor e ator Kenneth Branagh, lançada em 1995.

O conceito de mito é amplo. Neste trabalho, devido às suas opções teóricas, será adotada a formulação de Erich Fromm. ${ }^{9}$ Ele o caracteriza como uma história, desenrolando-se no tempo e no espaço, exprimindo, em linguagem simbólica, "experiências da alma".

O romance de Shelley percorre a trajetória de uma subjetividade, Frankenstein, criado pelo médico, Victor Frankenstein, em laboratório. Carrega as influências das idéias de Charles Darwin, mas enseja diferentes leituras. Dentro de uma perspectiva psicanalítica, é fundamental o resgate das pronúncias inconscientes, subjacentes ao mito do personagem.

O médico, Victor Frankenstein, se identifica: "Sou um cientista". Ele busca ter o controle sobre a vida e sobre a morte. É o seu sonho, que deseja tornar realidade. Com restos de cadávares, dá vida a uma criatura: Frankenstein, que acaba fugindo de seu criador. Ambos, contudo, não conseguem se separar. "Há um elo visível entre nós", admite o médico.

O mito da criatura se estabelece pela interrogação primordial: Quem sou eu?. É a secreta e cíclica incógnita, que habita a equação de sua alma. Não há resposta. Falta uma solução. Ele está perdido nas brumas da alienação de seu Ego. Não conhece a si mesmo.

Freud $^{10}$ já demonstrou o ritual ideológico que envolve um nascimento. Muitas vezes, antes de chegar ao mundo, a criança já está sendo instaurada como sujeito. A ideologia familiar antecipa-lhe uma série de características: ela terá o nome do seu pai, terá, portanto, uma identidade, e será insubstituível.

Frankenstein nasceu órfão deste ritual. Está despido de uma identidade. Não possui um nome, significante de singularidade, espécie de moeda que assegura as trocas simbólicas do conhecer e de ser reconhecido, de interpelar e de ser interpelado. Prossegue estagnado na condição de indivíduo. Não tem o passaporte mínimo para percorrer a dialética da sujeição.

O impasse ocorre pela ausência de nomeação. Ele não recebeu tal bênção familiar. A autonomeação de Frankenstein, ou nomeação pela pronúncia de terceiros, sem o sotaque do pai e da mãe, não é uma solução, mas apenas a transferência do conflito.

Frankenstein é um sobrenome. Só que a criatura não tem um nome. Resta apenas um vazio, onde deve pairar Frankenstein, sem base, sem âncora para se sustentar. O sobrenome passa, dicotomicamente, a funcionar, também, como nome.

Quando encontra o professor cego, De Lacey, Frankenstein não sabe responder quem ele é. Falta-lhe o significante batismal do simbólico: o nome. O interlocutor contorna o impasse. Identifica-se e revela os seus objetivos, com clareza, em duas falas:

9 FROMM, Erich. A linguagem esquecida. 6. ed. Rio de Janeiro: Zahar, 1976, p. 144.

10 FREUD, Sigmund apud ALTHUSSER, Louis. Aparelhos ideológicos de Estado. 2. ed. Rio de Janeiro: Graal, 1985, p. 98. 
- Meu nome é De Lacey...

- Vou lhe ensinar tudo o que puder. Serei o seu tutor.

O simbolismo decupa a cena, com traços de excelsa criatividade. De Lacey traz o visitante para perto de uma pequena e rústica lareira, para, nela, aquecer as suas mãos. Antes, já adiantara para o recém-chegado: Ninguém the fará mal aqui.

O calor da lareira não é uma simples referencialidade, posta aos pés do cenário. Significa que, naquela pobre e marginal cabana, havia a riqueza do calor humano. Ali, a circulação de trocas afetivas não estava minada por obstáculos conflitivos. Não era um bem negado e denegado, pois as mãos abertas, transparentes, eram instrumentais de doações recíprocas e constantes de afeto.

De Lacey vai representar um prefácio familiar para Frankenstein. Insere-o no âmbito da linguagem. Ensina-the a ler, a comer. Concede-lhe uma perspectiva de transcendência pela leitura da Bíblia e o mito da criação do mundo, de Adão e Eva, feita por Deus. Também, dá-lhe lições de afetividade, emblematizada pela palavra amigo.

Erik Ericson ${ }^{11}$ observa a fundamentalidade dos pais, da mãe, dos professores e dos pares, para a construção da subjetividade. Eles representam os modelos, os paradigmas, os referenciais, nos quais nos miramos, nos descobrimos numa simbiose, efetivada pela relação de imagem e semelhança, tão essencial no texto bíblico, para interpretar a criação divina.

De Lacey desempenha o papel da socialização de Frankenstein. Assume uma tríplice funcionalidade: na configuração de tutor, sintetiza as figuras do pai, da mãe e, acresce a elas, a do professor. Passa a ser o parađigma, o modelo, os referenciais para o visitante.

Até então, Frankenstein, tal qual o recém-nascido, mas órfão de família, era um indivíduo, dominado pelos instintos. Estava respaldado e sustentado pela sua dimensão biofísica. As suas ações eram determinadas, neste sentido, pelo Id, sem qualquuer internalização de normas sociais e sem um departamento de censura. Não possuía um Superego.

De Lacey resgata-lhe a fase oral. Ensina-lhe não somente a etiqueta, prescrevendo os bons modos ao comer, mas, ainda, o prazer do alimentar-se. A libido de Frankenstein ganha expressão, resgatando o estágio primordial do processo de sujeição. Se não conquista um nome, ele tem uma referencialidade, icônica pela aquisição do vocábulo amigo. $\mathrm{O}$ anfitrião enseja-lhe, minimamente, o estabelecimento de um Superego.

O assassinato do tutor, por dois ladrões, facilitou a liquidação do Complexo de Édipo de Frankenstein. Ele não precisou matar, simbolicamente, o pai, para ficar com a mãe. Os dois, sintetizados na pele do tutor, morrem, ao mesmo tempo, com o desaparecimento deste.

A vingança de Frankenstein, matando os assassinos, apresenta duplo sentido. Em nível objetivo, representou a reação diante da perda de um ente querido, mas, em nível subjetivo, simbolizou o roubo de não ter a possibilidade de matar De La-

11 ERIKSON, Erik apud COMIOTTO, Mirian S. Anotações de aula. Porto Alegre: Desenvolvimento Humano e Educação, PUCRS, 1995, p. 10. 
cey. Legitimado pela auto-imagem de um vingador, que promoveu a justiça com as próprias mãos, ele liquida o seu Édipo em harmonia consigo mesmo.

A criatura se volta para o seu criador. Aproxima-se do castelo de Victor. Nas redondezas, encontra o irmão do médico, William, um menino, acompanhado pelo seu cão. Este, assustado, lança a interrogação primorđial para o estranho:

- Quem é você?

A resposta veio:

- Amigo...

Os dois acabam se abraçando. Frankenstein, todavia, sem ter a noção da fragilidade da infância. Por inadvertência, acaba apertando em demasia William, que morre. À procura do menino, Justine, uma amiga da família, o encontra sem vida. É surpreendida por Frankenstein e, ao fugir, cai em um penhasco, morrendo também.

A morte de William foi emblemática. Metaforizou o problema de resgate, vivido por Frankenstein. Ele nasceu já adulto. Não teve as fases da existência em sintonia com as suas respectivas faixas etárias. Não desfrutou da infância, uma fase morta em sua vida, recuperada, com brevidade, fora de época, na casa de De Lacey.

A fuga de Justine, que a levou, também, para a morte, vai marcar os passos existenciais de Frankenstein. Foi o primeiro sinal, mais explícito, da rejeição feminina. Ele não teria chances com uma mulher normal. Superficialmente, a causa estava na sua feiúra.

Outra vez, no desamparo, Frankenstein busca o reencontro com Victor. Vale reproduzir alguns diálogos entre ambos em diferentes momentos. A criatura interroga o criador:

- Quem sou eu?

O médico responde:

- Eu não sei. Eu criei você...

A réplica não tarda:

- Você é meu criador. Você é Deus...

É possível verificar que a criatura não identifica, em Victor, a figura paterna, histórica, pois esta já fora assumida no seu universo simbólico por De Lacey. O médico é visto como o Pai Absoluto - Deus - que o colocou no mundo, sem um nome, contraditoriamente, órfão do simbólico.

Em sua cegueira, De Lacey fora o seu melhor e talvez único espelho. Não tivera olhos para a sua feiúra, porém lhe oferecera as mais belas janelas da alma, voltadas para a planície do amor. Um bom espelho não nega bons reflexos. Faz a transferência imaginária, sem cobrar ágio, nem pedágio.

A feiúra da criatura não é um significante, somente um significado, quer dizer um sintoma. Ela é uma decorrência da catatimia - a caricaturização do corpo, realizada pela carência afetiva. O problema interno busca a manifestação no externo, como forma de permanecer insolúvel.

A libido de Frankenstein já se manifesta pela sexualidade. Se Victor foi o seu Deus, ele é Adão e, portanto, deseja uma Eva. Reivindica o seu outro eu, feminino, 
submetido ao mesmo modo de nascimento. Não quer correr os riscos de uma rejeição que, à primeira vista, seria pela sua disformidade.

- Eu tenho sentimento. Não estou morto. Eu não quero ficar sozinho. Você me deu vida, por que não me deu alma?

A necessidade de socialização do homem fica evidente. Ninguém consegue viver sozinho. Ninguém possui auto-suficiência, que possa descartar a presença do Outro. A própria gênese da subjetividade tem como pré-requisito um Outro, como relação entre criador e criatura.

O termo alma não é denotativo, mas trabalha a conotação. Estabelece a ausência do amor familiar, condição imprescindível para a construção de um ser com personalidade equilibrada, em que a felicidade não seja uma propriedade apenas da ficção, mas que apresente as cores da realidade.

Para compreender o espelho, Victor, basta mirar os seus reflexos, Frankenstein. O médico lembra a canção, Como nossos pais, de Belchior, interpretada por Elis Regina. Os versos referem: "Você me pergunta pela minha paixão; Digo que estou encantado com uma nova invenção".

Noivo de Elizabeth, Victor colocou a amada no freezer. Secundarizou a relação. Priorizou a invenção. Desejava ser pai, mas sem um ato de amor. Não queria desenvolver a paternidade como um homem comum. Chamava para si a incumbência e a identificação de um Pai Absoluto - o Criador.

Victor recalcou os apelos do amor. Preferiu sublimá-los apostando todas as suas fichas nas gratificações da cientificidade. A ele, não bastaria uma felicidade dentro dos limites do compasso da realidade. Desejava muito mais. Reivindicava uma condição de Absoluto, única resposta compatível com as exigências de sua idealidade, reveladoras de suas insatisfações com o seu Ego.

Nos conflitos neuróticos, vale a predição do senso comum: "A emenda é pior do que o soneto". O médico tentou sublimar a sua incapacidade de amar. Acabou transferindo o seu desamor para a sua invenção. A criatura saiu à imagem e à semelhança do seu criador. Por isso, ambos são inseparáveis.

Mesmo que a criatura tivesse uma família em um clima de normalidade, não seria suficiente. Precisaria, ainda, contar com o amor familiar. Sem este, as pessoas estão alheias de si mesmas e se vêem, imaginariamente, como monstros, sem o serem. São Frankensteins, com nome e sobrenome, definidos na Carteira de Identidade. Carregam, na alma, o calvário silente, traçado pelo peso invisível da cruz do conflito neurótico: o mito do amor negado e denegado. 